Joseph T. Tennis. 2011. Ranganathan's layers of classification theory and the FASDA model of classification. In Smiraglia, Richard P., ed. Proceedings from North American Symposium on Knowledge Organization, Vol. 3. Toronto, Canada, pp. 185-

Joseph T. Tennis (jtennis@uw.edu) University of Washington Information School, Seattle WA USA

\title{
Ranganathan's Layers of Classification Theory and the FASDA Model of Classification
}

\begin{abstract}
Describes four waves of Ranganathan's dynamic theory of classification. Outlines components that distinguish each wave, and porposes ways in which this understanding can inform systems design in the contemporary environment, particularly with regard to interoperability and scheme versioning. Ends with an appeal to better understanding the relationship between structure and semantics in faceted classification schemes and similar indexing languages.
\end{abstract}

\section{Introduction}

The increasing popularity of tagging, ontology engineering, and information architecture has brought the concepts of classification theory into the zeitgeist of organizational management, science, and business. A popular press example, a book by David Weinberger, draws a caricature of Shiyali Ramamrita Ranganathan as a disciple to mystics and an overly-meticulous traveler (Weinberger, 2007, 85). Although some teachers laud Weinberger's description of facets, it seems that he fails to comprehend the full host of Ranganathan's theories and how they are relevant to developing and evaluating information systems today.

Through his long and prolific career S. R. Ranganathan worked toward a coherent and robust theory of classification - a Dynamic Classification Theory. In working toward this goal he developed four successive waves of classification theory. They were: Faceted, AnalyticoSynthetic, Depth, and Abstract Classification (FASDA together) (Ranganathan, 1967; 1953). These, listed in roughly chronological order, represent the advancement of his thinking, along with that of his close circle of collaborators and students. We can distinguish between waves by the various layers Ranganathan added to the act of classification. In turn, we see these layers by understanding the components of his complex and ever-evolving theory. Facets constitute but one of those components. Facets, when layered with other components discussed from 1930s to the 1950s form the wave of Faceted Classification.

Faceted Classification is a method of breaking the universe of subjects apart into facets. Faceted Classification was based on canons, many adapted from Sayers's work, but Ranganathan expanded and refined them. However, he saw its shortcomings. Where Faceted Classification was rigid, Analytico-Synthetic Classification, the second wave, was more flexible and provided a number of techniques that allowed the classifier more expressive power. We can mark the birth of Analytico-Synthetic classification with a paper in 1950 (Ranganathan 1951). Depth Classification was an offshoot of, yet contemporaneous to, the former, focused on domains requiring richer expressive classificatory power. I place its formal genesis in 1953 with the conference on Depth Classification and Reference Service (Ranganathan 1953). Finally, Abstract Classification, the last wave Ranganathan introduced, was seen as a method whereby classification research could create models of classification. Building on proceeding research, Abstract Classification could generalize from practice, create models of how classification could 
be done, and through comparative research efforts on this level, expand the techniques available to the classificationist in creating better schemes. This line of thinking surfaces in the 1960s.

This stands as one body of coherent thought, separable into layers, but requiring investigation to make sense of it. That is, to date we have no comprehensive textbook that outlines all the components of the evolving thought of Ranganathan. All we have is his scattered and sometimes contradictory oeuvre. He wrote on classification from the 1930s until his death in 1972. I hope this is one small step toward a more systematic view of this body of knowledge.

It goes without saying that facets and faceted classification are popular topics today in information system design. Even without the aforementioned textbook, we still talk of facets in the research and professional literature, yet little work is done in the vein of Ranganathan, or with explicit acknowledgement of one or more of these waves of classification theory. What citations there are seem simply to be polite recognitions that facets are the stuff of Ranganathan; nothing more.

In this paper I present a model of Ranganathan's classification theory. My aim here is to present the layers his thought, as I understand them, in a systematic and simpler, but not simplified manner, that is, without losing the integrity of what I see as his intent. Ranganathan was not only concerned with facets. They were one part of his approach to designing and successfully using classification. The reason for presenting Ranganathan's theory in the form of a model is one rooted in activism. I want to provide a map, as I see it, of his work, so that others might do more work in this area, expanding on his foundations, and making this work relevant to the contemporary context of the Semantic Web, while demonstrating how we might advance classification theory through discussions that use this theory and build on it.

\section{Rationale}

Time, money, and effort have been thrown into the development of ontologies and other classificatory structures for the Semantic Web. Likewise, work has been done on the Simple Knowledge Organisation Structure (SKOS), which is currently the de jure standard of exchanging information about classification schemes over the web. Ranganathan's classification theory, and its director descendants, has much to say about how this work should be modeled, and as a consequence how structures and standards should be designed and evaluated. This paper develops an analytical lens from Ranganathan's waves of classification theory; useful, it is hoped, to research on scheme design and evaluation.

\section{Methodology}

The materials necessary for this work were (1) Ranganathan's theoretical works (e.g., 1937, 1953, 1957, 1965, 1967), (2) contemporarily and posthumously published classification schemes (e.g., 1989) and (3) a selected lineage of papers indebted to and building directly on (i.e., citing) Ranganathan's conceptions of classification (e.g., Svenonius 1979, Neelameghan 1997). The process of distilling core tenets required reading and comparing different presentations of his work, comparing terminology to conceptual definitions. This allowed me to identify and formalize the most current state of his thought. His own work changes over the course of his lifetime, so that terminology is not always presented consistently, and concepts often change based on their relationship with other concepts of his system. This resulted in (a) a list of 
components that constitute the defining characteristics of each wave, (b) a set of Ranganathan's Models of classification actions, and (c) additions to these models through subsequent research. I present a sample of these below, with full models to be published elsewhere (Tennis 2011).

The epistemic stance taken by the researcher is a neo-pragmatic one (Rorty, 1982, 1999), which takes both text and social acts as the same palette for the social scientist's interpretation. These sources of evidence reveal insight into the use of theories for action i.e., development, implementation, and evaluation of classification schemes - bound to an ontology of collective shared understanding. The epistemic stance is an important part of social science methodology. By stating the epistemic stance, researchers can make clear the knowledge claims that follow from their research. In this case, I am using Rorty’s conception of social science, which allows me to construct a narrative (in the form of components lists and models) about extant research on classification.

\section{Findings}

\subsection{The Waves, Their Layers, and Their Components}

The waves of Ranganathan's theory can be identified by the identification and definition of different components giving rise to differentiations between previous thought and subsequent thought on classification. Thus, each of the waves has a set of components. The sum of the components is a layer. Each wave subsequently adds, reorganizes, renames, or redefines these components. Very rarely are whole components taken away. Rather, we will see a renaming or a new definition of a component.

The waves can be schematized in the follow table. Following the table I discuss each of these components.

\begin{tabular}{|c|c|c|c|c|}
\hline & $\begin{array}{l}\text { Faceted } \\
(1924- \\
1949)^{1}\end{array}$ & $\begin{array}{l}\text { Analytico- } \\
\text { Synthetic } \\
\text { (1950- } \\
\text { Present) }\end{array}$ & $\begin{array}{l}\text { Depth (1953- } \\
\text { Present) }\end{array}$ & $\begin{array}{l}\text { Abstract (1965- } \\
\text { Present) }\end{array}$ \\
\hline Facets & $\begin{array}{l}\text { Unrounded } \\
\text { and } \\
\text { Unleveled } \\
\text { and } \\
\text { Unquasi-ed }\end{array}$ & $\begin{array}{l}\text { PMEST, } \\
\text { Rounded, } \\
\text { Leveled, } \\
\text { Emptied }\end{array}$ & $\begin{array}{l}\text { PMEST, } \\
\text { Rounded, } \\
\text { Leveled, } \\
\text { Emptied, (W) } \\
\text { analysis, (QI) } \\
\text { analysis, } \\
\text { Zoned and } \\
\text { Sectored }\end{array}$ & $\begin{array}{l}\text { PMEST, Rounded, } \\
\text { Leveled, Emptied, } \\
\text { (W) analysis, (Q1) } \\
\text { analysis, Zoned } \\
\text { and Sectored, } \\
\text { Grammataographal }\end{array}$ \\
\hline Base & Robust & Thin & Brittle & Reinvested \\
\hline Notation & "Meccano" & “Grammatical” & “Telescoping” & "Mnemonic" \\
\hline $\begin{array}{l}\text { Connecting } \\
\text { Digits }\end{array}$ & 1 & Many & Many & $\begin{array}{l}\text { Many and linked } \\
\text { to linguistics } \\
\text { research }\end{array}$ \\
\hline$\overline{\text { Laws }}$ & $6^{3}$ & $\begin{array}{l}8 \text { (2 don’t } \\
\text { appear again) }\end{array}$ & $7(11)^{5}$ & $\begin{array}{l}\text { A source of more } \\
\text { Laws }\end{array}$ \\
\hline
\end{tabular}


Joseph T. Tennis. 2011. Ranganathan's layers of classification theory and the FASDA model of classification. In Smiraglia, Richard P., ed. Proceedings from North American Symposium on Knowledge Organization, Vol. 3. Toronto, Canada, pp. 185-

\begin{tabular}{|l|l|l|l|l|} 
Canons & 28 & 31 & 43 & $\begin{array}{l}\text { A source of more } \\
\text { Canons }\end{array}$
\end{tabular}

Table 1. Component Comparison of Ranganathan’s Waves of Theory

The above table outlines 6 components that are useful in distinguishing Faceted Classification from three other waves of classification theory. These six form a common layer that spans FASDA. The components in this layer are (1) Facets, (2) Base, (3) Notation, (4) Connecting Digits, (5) Laws, and (6) Canons. To create a scheme for classifying subjects, Ranganathan felt all of these were important to reducing an $\mathrm{N}$-dimensional universe to a single line - that is, taking the infinite universe of subjects with their myriad interrelationships and making systematic, comprehensible, and helpful the shelf of a library.

Faceted Classification, the first wave of Ranganathan's theory, is distinguished from the others in along the components: (1) the lack of fundamental categories or rounds and levels in the classification, (2) a base notation (mixed with letters and numbers), that is satisfactory to the purpose, (3) a rudimentary approach to hospitably expressive notation, with no emptying digits for interpolation or extrapolation in array, (4) fewer connecting digits which limited the extrapolation and interpolation in chain as well as rendered the notation by colon alone inelegant and non-parsimonious, (5) and fewer laws, and canons. Faceted Classification is barebones. Its universe of application was restricted to subjects, but was not yet applied to schedules of classification of great extent, so seemed to fit the purpose. It is, in theory, flexible, but only to a point. It does not yet guide the design of schemes for classification that are infinitely hospitable and parsimoniously expressive. This is because we cannot interpolate or extrapolate in array, nor do we have notation that allows for the expression of that. That is, we could not add new facets in the proper place such that the subjects would fall into a helpful sequence. A scheme for classification built according to Faceted Classification theory is rigidly faceted (Ranganathan 1967, 107).

The second wave, Analytico-Synthetic Classification adds many characteristics to facets that aid Ranganathan's purpose. In Analytico-Synthetic Classification we add the fundamental categories of Personality, Matter, Energy, Space, and Time (PMEST), which were only intuitively present in the early classification schedules and theory. In this second wave, Ranganathan adds more digits to the classification notation. He adds connecting digits to express these fundamental categories and their citation order. This allowed him to express rounds and levels in his notation, making way for fully expressive notation in order to represent very complex subjects (i.e., subjects with many facets). Analytico-Synthetic classification also allowed for notational expansion through emptying digits. This innovation allowed for interpolation and extrapolation in array. Analytico-Synthetic classification was guided by postulates and principles (Ranganathan 1967, 109-110). It was also the zenith of applied classification theory for general collections.

The closely related third wave is Depth Classification. The novelty of Depth Classification lies in its Whole and Part-Whole (W) analysis, Quasi-Isolate Analysis (QI) and a focus on Zones and Sectors. With the desideratum of making very specific assertions about subjects in very particular domains, Ranganathan introduces a set of components that accommodate that desire. The design requirements of Depth Classification dictate that we must be able to add a large 
number of very specific facets while maintaining the semantics of the digits present.

Furthermore we must be able to file those digits in the proper sequence - no matter how many there are, and no matter how precise they are. Interpolation and extrapolation are required, but semantically rich and systematically precise notation is jeopardized because of the limitation of notation as understood in earlier incarnations of the dynamic theory of classification. Ranganathan then adds analysis techniques to accommodate the constraints of using alphanumeric symbols to represent the order and meaning of ideas. This analysis is the whole and whole-part analysis which results in different sectors and zones of notation. The complexities of this are worked out such that each array and chain has expressive notation regardless of how many ideas occupy a coordinate space in the classification schedule. That is, Depth Classification wants all characteristics and levels in the classification to be clearly and parsimoniously represented.

Finally, Abstract Classification is more about moving classification from trial-and-error empirical methods to postulational methods of thought, following the analogy of mathematics moving from applied mathematics to pure mathematics. That is, with enough data from the practice and reflection of classification, Abstract Classification can weigh the constraints and functional requirements, and then create more features of the classification system in the hypothetical, such that when applied to the work of classification, it maximizes the implementation of the desired results.

Besides being the reflective outcome of work on classification up to the 1960s, Abstract Classification focused on the power of notation to fulfill Ranganathan's desire for parsimonious and mnemonic representation. It was grammatographal insofar as Abstract Classification, as outlined in his 1967 Prolegomena, hoped that innovation in notation would aid the complex and growing requirements to faithfully represent the universe of subjects in a hierarchical, helpfully ordered, mutually exclusive, and jointly exhaustive scheme for classification.

Few worked in Abstract Classification besides Ranganathan, though it holds potential for a fruitful understanding of structure in relation to semantics of classification schemes as a particular kind of indexing language (c.f. Svenonius 1979).

\subsection{Summative Model of FASDA as Seen by the IDEF0 Formalism}

Modeling Ranganathan's theory in an IDEF0 formalism lends a focus on the actions. This formalism allows us a bird's-eye view of the actions, inputs, outputs, constraints, and mechanisms of complex processes. I have provided the diagrams that I generated in modeling FASDA in IDEF0 elsewhere (Tennis 2011). And while the diagrams are too large and complex to present here, I will present some findings based on looking at them. Below is a table that outlines the differences and one commonality of the waves of classification theory developed by Ranganathan.

\begin{tabular}{|l|l|l|l|l|}
$\begin{array}{l}\text { Postulational } \\
\text { Work / } \\
\text { Actions }\end{array}$ & $\begin{array}{l}\text { Faceted } \\
(1924-\end{array}$ & $\begin{array}{l}\text { Analytico- } \\
\text { Synthetic } \\
(1949)^{6}\end{array}$ & $\begin{array}{l}\text { Depth } \\
(1950-\end{array}$ & $\begin{array}{l}\text { Abstract (1965- } \\
\text { Present) }\end{array}$
\end{tabular}




\begin{tabular}{|c|c|c|c|c|}
\hline $\begin{array}{l}\text { Facet } \\
\text { Sequence }\end{array}$ & & & & Research \\
\hline $\begin{array}{l}\text { Analysis into } \\
\text { Fundamental } \\
\text { Categories }\end{array}$ & Not present & $\begin{array}{l}\text { In rounds } \\
\text { and levels }\end{array}$ & $\begin{array}{l}\text { In many } \\
\text { rounds and } \\
\text { levels }\end{array}$ & $\begin{array}{l}\text { Subject of } \\
\text { Research }\end{array}$ \\
\hline $\begin{array}{l}\text { Analysis } \\
\text { Whole-Part }\end{array}$ & Not present & Not present & Present & $\begin{array}{l}\text { Subject of } \\
\text { Research }\end{array}$ \\
\hline $\begin{array}{l}\text { Analysis of } \\
\text { Documents }\end{array}$ & Not present & Not present & Not present & Not present \\
\hline $\begin{array}{l}\text { Separate } \\
\text { Universe of } \\
\text { Ideas into } \\
\text { Sectors and } \\
\text { Zones } \\
\end{array}$ & Not present & Nascent & $\begin{array}{l}\text { Fully } \\
\text { present }\end{array}$ & $\begin{array}{l}\text { Subject of } \\
\text { Research }\end{array}$ \\
\hline $\begin{array}{l}\text { Discern } \\
\text { Compound, } \\
\text { Complex, } \\
\text { Macro, } \\
\text { Micro, or } \\
\text { Spot Subjects }\end{array}$ & Not present & Present & Necessary & $\begin{array}{l}\text { Subject of } \\
\text { Research }\end{array}$ \\
\hline $\begin{array}{l}\text { Evaluate } \\
\text { Classification }\end{array}$ & Few Laws & $\begin{array}{l}\text { Many Laws, } \\
\text { Postulates, } \\
\text { and } \\
\text { Principles }\end{array}$ & $\begin{array}{l}\text { Many Laws, } \\
\text { Postulates, } \\
\text { and } \\
\text { Principles }\end{array}$ & $\begin{array}{l}\text { Generates } \\
\text { criteria for } \\
\text { classification, } \\
\text { Looking } \\
\text { outward to other } \\
\text { philosophical } \\
\text { grounding(s) }\end{array}$ \\
\hline
\end{tabular}

Table 2. Postulational Work and Actions

We can see from this table that Analytico-Synthetic and Depth Classification are more similar than either is to Faceted Classification. Yet, we can see how the actions required of the classifier-cum-classificationist increase in complexity as we move from left to right. Ranganathan's successive waves of classification theory required more and more of the classifier. Yet, we see very little attention being paid to what has dominated subsequent classification and indexing theory: the analysis of documents for their subjects. For Ranganathan, in each of his waves, the title was enough material to go off of, at least formally, to do the work required to place the document-in-hand into its most helpful place on the shelf. Here is one action, indexing, represented by a rich literature, that could be incorporated into this dynamic theory of classification.

\subsection{Implications for Interpretation vs. Structuration of Classes and their Characteristics (first Order Classificatory Processes)}

As you can see from the table above, we have a clear picture that Ranganathan was focusing his attention on how to structure representations, and paid little attention to interpretation issues. This concern comes later in classification theory (c.f., Beghtol 1986; Mai 2001; Mai 2005; Hjørland 2002). This leaves us to believe that the way Ranganathan structured his facets and 
Joseph T. Tennis. 2011. Ranganathan's layers of classification theory and the FASDA model of classification. In Smiraglia, Richard P., ed. Proceedings from North American Symposium on Knowledge Organization, Vol. 3. Toronto, Canada, pp. 185-

ancillary components of his theory is independent of the concerns of interpretation as we now understand them. This leaves us with a question: if we follow the need for faceted classification, what is the relationship between facets and interpretive work like Beghtol's, Mai's, and Hjørland's.

Another finding is that Ranganathan's dynamic theory of classification is more than a collection of facets, and more than facets tied to fundamental categories. The other parts of his classification theory deal with the ontology of facets as atomic units of meaning. And this comes with advantages and with problems.

We can see surfacing from his rather pragmatic trial-and-error method that the closer we try to control definitions of and relationships between atomic units of meaning, the more complex it becomes. The expressive power of natural language is an aloof goal for the expressive power of notation in classification. And we see when we compare the different generations of Ranganathan's theory that the more analysis done, the more notation is needed. Some notation is even changed to represent this kind of expressivity. The question for theorists is, what is the relationship between structure, as represented by notation (its ordering power and expressive power in a scheme for classification) and how we interpret subjects, no matter how complex. That is, what do we privilege when we are trying to assemble a picture of the universe of knowledge from tiny pieces and using notation? Ranganathan privileged mechanical expressiveness. Not all theorists do, and not all schemes do. Some rely on terminological access to aid retrieval and find structure an added bonus, not an ultimate design goal. For us to fully understand the benefits of one or the other, we must understand this trade-off between structuration and interpretation.

\subsection{Implications for Interoperability and Scheme Versioning (the Second Order Classificatory Processes)}

Building off of the above questions and assertions, we can reaffirm the relevance of this theoretical work in the contemporary environment. On the web, we are building classification schemes that have to interoperate and because they are digital we can manage them over time in new and more thorough ways. This requires a reinvestment in understanding the finer points of theories of faceted classification.

I make the argument here that contemporary work on conceptions of interoperability and scheme versioning are a logical extension of both Analytico-Synthetic Classification and Abstract Classification, and can be read through a Ranganathan-informed lens. This is done by defining the components of Ranganathan's waves of classification theory with a formal modeling language, IDEF0. Formalizing these parts of his oeuvre generates an analytical evaluation tool, based on a theoretical standard. This work is similar to standards development (see ISO 59631985) with the exception that it is informed strictly by one theoretical school, yet the result is a similar abstraction of the process and products of classification, which can be used to guide, measure, and assess the quality of implementations.

We can also see how theory, in the case of Ranganathan's work, has built over time, and accumulated complexity to address information organization challenges. This too is a lesson we 
can learn as theorists, and perhaps we can advance this work by understanding where FASDA left off, and where these waves of classification theory lead us.

First, interoperability, the ability of systems to work together, requires that we understand the structure of meaning of at least two systems. The methods by which we understand the structure of meaning requires us to document the means of system creation, its structure, and the work practices that maintain that structure. As discussed elsewhere, structure is "constructed space consisting of a set of internal partitions, each of which is connected to other partitions in the set in a meaningful way, either as a linear sequence (i.e., a continuum or process) or a network of links (i.e., a web) at the lower levels or as a hierarchical or polyhierarchical organization of partwhole and/or is-a relationships at higher levels," (Tennis and Jacob 2008). Since facets and the ancillary atomic units in each wave of FASDA constitute the base structure, we must understand these in relation to other systems which have what Ranganathan calls monolithic numbers, and therefore carry different levels of hierarchy. Likewise, a facet is not a facet by any other name. Understanding the structural nature of facets in all their forms (Ranganathan-like or not) will aid in building systems that work together.

Second, scheme versioning, and specifically the tracking of changes that are made in classification schemes or other indexing languages, requires knowing the structure of meaning in one scheme at one point in time. As we now understand, schemes can change in three major ways: structural, word-use, and textual changes (Tennis 2007). While word-use and textual changes (that have to do with what words are associated with classes and what documents are associated with classes over time respectively) are universal changes across indexing languages, structural changes in the FASDA context are theory-dependent. That is, if we see a faceted classification scheme and we want to manage how it changes over time, we must understand that there are different conceptions of facets and their ancillary parts depending on which theoretical concerns made their way into the design of the structure. Thus, we must know the methods of design to fully accommodate methods of implementation and maintenance over time. Understanding the dynamic theory of classification as waves in a FASDA model, helps us with that.

\section{Conclusion}

Ranganathan talked about how one generation of his thought superseded another. This, in fact, was the reason for his call to Abstract Classification work - to formulate a methodical progress. However, this is not part of our current thinking in classification theory. Much can be learned about the relationship between structure and semantics, and what classification structures allow and restrict when we probe deeper into this body of work. No where else has such a deep design method surfaced. We can conclude by making the following statements about what we gain from studying these models of FASDA.

First, the concept of extension and intention is both an aid and an inhibitor to creating a dynamic theory of classification. If we assume that classes built from basic subjects and isolate ideas, then we have a spatial metaphor that is essential and reinforced in our analysis of classification both the act and the structures representing classes. More work into the relationship between structure and semantics (interpretation) is needed. 
Next, we gain a deeper appreciation for his concern with words (what he called the verbal plane). Though much of what Ranganathan discuses is his Idea Plane and Notational Plane, we do see, once we model the actions of classification in the IDEF0 diagrams how much text and interpretation is prescribed in this work. This means we have to reckon with the textual evidence present to do classification work, including, but not limited to, his Laws. Words abound in this space, and the ideal of the Idea Plane is real, it is only manifest through the verbal plane and the written word. This has implications for what we document in an online environment in relation to the implementation of faceted classification and related indexing languages.

Finally, what do we gain from studying Ranganathan's theory this way? We understand how current thought could help inform a complete picture of dynamic classification.

Understanding Ranganathan in all his complexity and in his own terms is an important to advancing classification theory. Like Schenkerian Analysis in music theory, we must understand the form of classification, comparing the basic pieces and the ideal types. Where Schenkerian Analysis constructed a model of Western tonal music, Ranganathan constructed a model of hospitable and coextensive classification. Schenkerian Analysis is about learning how to hear a piece of art music. Ranganathan's theory of dynamic classification is about learning how to see classification. Both require training and both are forms of art appreciation, and whether it be sound or subjects both provide insight into this human work of putting things in order. 


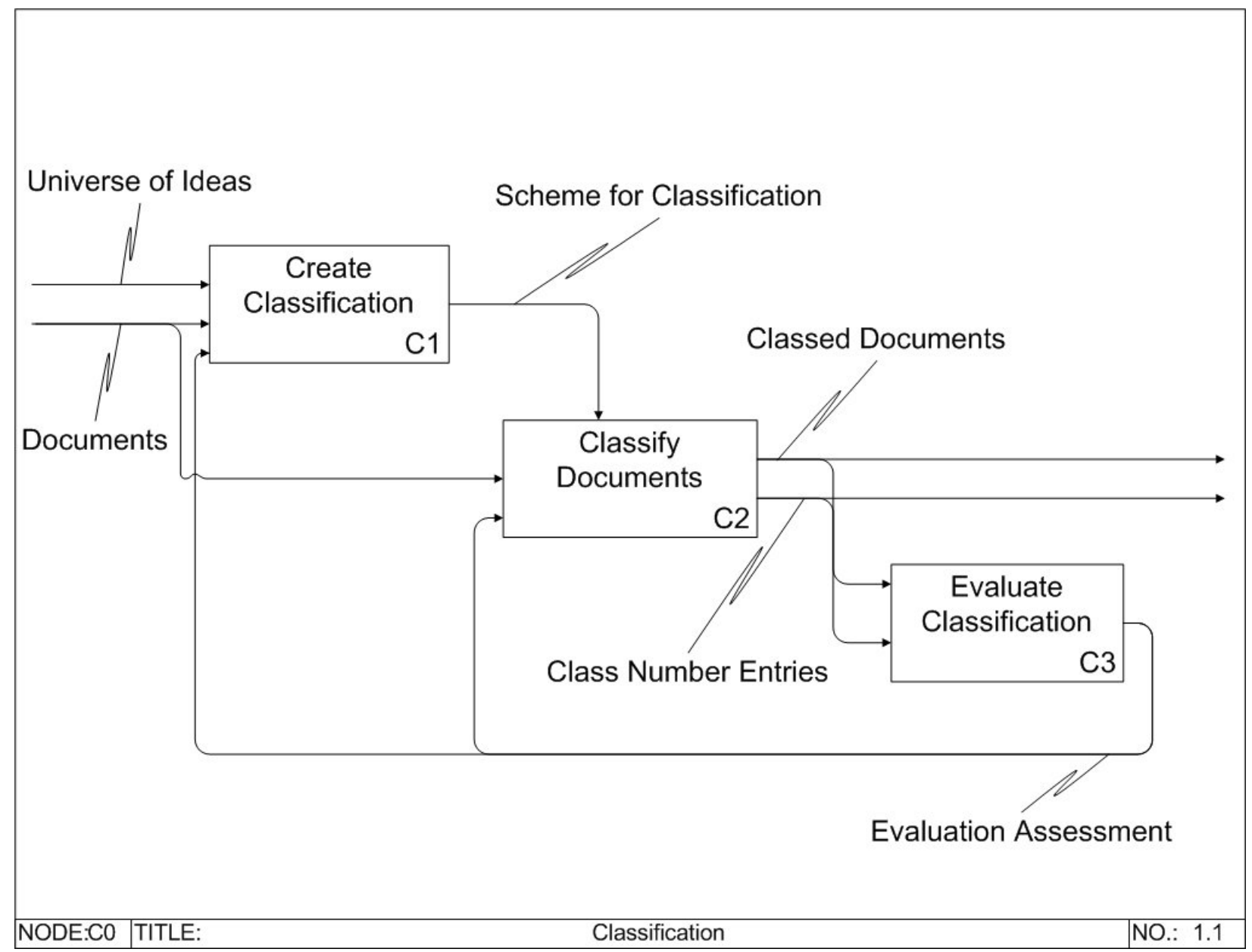

Example of IDEF0 Model of Ranganathan’s classification theory.

\section{References}

Beghtol, C. (1986). "Bibliographic classification theory and text linguistics: aboutness analysis, intertextuality and the cognitive act of classifying documents." In Journal of Documentation 42(2):84-113.

IDEF0 Function Modeling Method. Overview available: http://www.idef.com/IDEF0.htm ISO 5963-1985. Documentation - Methods for Examining Documents, Determining Subjects, and Selecting Indexing Terms. International Organization for Standardization.

Mai, J-E. (2001). "Semiotics and Indexing: an Analysis of the Subject Indexing Process." In Journal of Documentation 57(5):591-622.

Mai, J-E. (2005) "Analysis in Indexing: Document and Domain Centered Approaches." In Information Processing and Management 41(3):599-611.

Neelameghan, A. (1997). S. R. Ranganathan’s Postulates and Normative Principles: Applications in Specialized Databases Design, Indexing, and Retrieval. (Bangalore: Sarada Ranganathan Endowment for Library Science).

Ranganathan, S. R. (1937). Prolegomena to Library Classification. (Madras: Madras Library Association).

Ranganathan, S. R. (1951). Colon Classification and Its Approach to Documentation. In Shera, J. H. and Egan, M. E. Eds. Bibliographic Organization: Papers Presented before the 
Fifteenth Annual Conference of the Graduate Library School July 24-29, 1950. (Chicago: University of Chicago Press).

Ranganathan, S. R. (Ed.) (1953). Depth Classification and Reference Service and Reference

Material: Papers for Discussion at the Tenth All-India Library Conference. Hyderabad, 14 June 1953. (Delhi: Indian Library Association).

Ranganathan, S. R. (1957). Prolegomena to Library Classification. 2nd Edition. (London:

Library Association).

Ranganathan, S. R. (1967). Prolegomena to Library Classification. 3rd Edition. (Bombay, India: Asia Publishing House).

Ranganathan, S. R. (1987). Colon Classification. 7th Edition. Revised and expanded by M.A. Gopinath.

Rorty, R. (1982). Consequences of Pragmatism. (Minneapolis, MN: University of Minnesota Press).

Rorty, R. (1999). Philosophy and Social Hope. (New York: Penguin Books).

Svenonius, E. (1979). "Translation between Hierarchical Structures: An Exercise in Abstract Classification.” In Third International Study Conference on Classification Research. Bombay, 1975. . (Bangalore, India: Documentation Research Training Centre).

Tennis, J. T. (2007). "Scheme Versioning in the Semantic Web.” In Cataloging and Classification Quarterly. 43(4/3): 85-104. Also published as a chapter in a book by Haworth Press.

Tennis, J. T. (2011). FASDA Diagrams. http://faculty.washington.edu/jtennis/

Weinberger, D. (2007). Everything is miscellaneous: The power of the new digital disorder. (New York: Times Books).

\footnotetext{
${ }^{1}$ Facet Analysis began in 1924 (Ranganathan 1967, 566), whereas Faceted Classification surfaces in 1933 with the first edition of the Colon Classification. This is a distinction (not consistently held) that we can do analysis without notation, but once we do analysis and add notation we are doing classification.

${ }^{2}$ Round and Level Analysis started in 1950, whereas Analytico-Synthetic Classification guided by Postulates and Principles begins in 1957 (Ranganathan 1967, 566).

${ }^{3}$ One of these Laws later becomes a Canon

${ }^{4}$ The two that do not appear again are the Law of Large Numbers and the Law of Probability

${ }^{5}$ There are seven laws if you count all of the Five Laws of Library Science as one; otherwise we have eleven Laws that govern the design of classification according to Ranganathan.

${ }^{6}$ Facet Analysis began in 1924 (Ranganathan 1967, 566), whereas Faceted Classification surfaces in 1933 with the first edition of the Colon Classification. This is a distinction (not consistently held) that we can do analysis without notation, but once we do analysis and add notation we are doing classification.

${ }^{7}$ Round and Level Analysis started in 1950, whereas Analytico-Synthetic Classification guided by Postulates and Principles begins in 1957 (Ranganathan 1967, 566).
} 